ASTHMA

\title{
Exhaled nitric oxide in the diagnosis of asthma: comparison with bronchial provocation tests
}

\author{
N Berkman, A Avital, R Breuer, E Bardach, C Springer, S Godfrey
}

Thorax 2005;60:383-388. doi: 10.1136/thx.2004.031104

See end of article for authors' affiliations

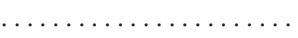

Correspondence to:

Dr N Berkman, Institute of

Pulmonology, Hadassah

University Hospital, POB

12000 , Jerusalem, Israel

il-91120; neville@

hadassah.org.il

Received 5 July 2004

Accepted 8 February 2005
Background: Bronchial provocation tests such as exercise, methacholine $(\mathrm{MCH})$, and adenosine- $5^{\prime}$ monophosphate (AMP) challenges are used extensively in the diagnosis of asthma. A study was undertaken to determine whether exhaled nitric oxide (eNO) can be used to diagnose asthma in patients with non-specific respiratory symptoms and to compare this test with conventional provocation tests.

Methods: Patients with non-specific respiratory symptoms and normal spirometric parameters were included in the study. eNO was measured and exercise, $\mathrm{MCH}$ and $\mathrm{AMP}$ challenges performed in all subjects. Patients were defined as asthmatic based on clinical follow up 24 months after testing.

Results: Forty patients were considered asthmatic and 45 were not. The area under receiver operating characteristic curves gave values of 0.896 for $\mathrm{eNO}, 0.781$ for exercise, 0.924 for $\mathrm{MCH}$, and 0.939 for $\operatorname{AMP}(p=0.033,0.575$ and 0.085 for eNO v exercise, $M C H$ and AMP respectively). From our data, a cut off value of $\mathrm{NO}>7 \mathrm{ppb}$ at a flow rate of $250 \mathrm{ml} / \mathrm{s}$ best differentiates between asthmatics and nonasthmatics (sensitivity $82.5 \%$, specificity $88.9 \%$ ). Optimal cut off values for other tests were exercise: $\Delta \mathrm{FEV}$ $\geqslant 10 \%$ (sensitivity $57.9 \%$, specificity $100 \%$ ); $\mathrm{PC}_{20}-\mathrm{MCH}: \leqslant 3 \mathrm{mg} / \mathrm{ml}$ (sensitivity $87.5 \%$, specificity $86.7 \%$ ); and $\mathrm{PC}_{20}-\mathrm{AMP}: \leqslant 150 \mathrm{mg} / \mathrm{ml}$ (sensitivity $89.5 \%$, specificity $95.6 \%$ ).

Conclusions: Measurement of eNO can be used as a safe, simple and rapid test for the diagnosis of asthma and is as good as bronchial provocation tests.
A diagnosis of asthma is made on the basis of compatible clinical symptoms and signs together with the presence of reversible airway obstruction as shown by pulmonary function testing. ${ }^{12}$ When in doubt, the diagnosis may be confirmed by performing bronchial provocation tests such as exercise, methacholine $(\mathrm{MCH})$, histamine, or adenosine $5^{\prime}$ monophosphate (AMP) challenges to demonstrate the presence of airway hyperreactivity. ${ }^{2-5}$ Although provocation tests are of great value, they are time consuming, costly, and bear a small risk of inducing severe bronchospasm. ${ }^{3}$ Furthermore, no single provocation test is considered the "gold standard" for the diagnosis of asthma. ${ }^{2-4}$ There is also controversy as to what extent airway hyperreactivity correlates with the degree of airway inflammation. ${ }^{67}$

Nitric oxide (NO) is detectable in the exhaled air of humans. An increase in the concentration of exhaled nitric oxide (eNO) has been found in asthmatic patients including those with mild disease. ${ }^{90}$ Levels of eNO parallel the inflammatory process in the asthmatic airway ${ }^{11-13}$ and treatment with anti-inflammatory drugs such as corticosteroids results in a marked reduction in these levels. ${ }^{14}$

Increased eNO is found in other inflammatory respiratory disorders including sinus disease, viral upper respiratory tract infection and lung transplant rejection, ${ }^{15-18}$ but not in patients with chronic obstructive pulmonary disease and cystic fibrosis. ${ }^{19} 20$ eNO levels are lower in cigarette smokers than in non-smoking controls. ${ }^{21}$

Although much has been published about the effects of various interventions on eNO levels, such as bronchial provocation tests ${ }^{22} 23$ and anti-asthma medications, ${ }^{14}$ until recently little had been published regarding the clinical utility of this test. Over the last 2 years several publications have shown that eNO is an excellent tool for the diagnosis of asthma. ${ }^{24-26}$ All of these studies used bronchial hyperreactivity and/or reversible airway obstruction to define asthma. We performed a prospective study in a select group of subjects using a clinical follow up of 24 months to define asthma, to determine the value of using eNO as a diagnostic test for asthma, and compared this with conventional bronchial provocation tests.

\section{METHODS}

Subjects

Patients with non-specific respiratory symptoms of at least 3 months' duration referred to the outpatient pulmonary clinic of Hadassah University Hospital for diagnostic evaluation and in whom the consulting respiratory physician considered the possibility of a diagnosis of asthma were included in the study. Patients with a clear alternative diagnosis, a previous diagnosis of asthma, or evidence of airway obstruction on baseline spirometry (forced expiratory volume in 1 second $\left(\mathrm{FEV}_{1}\right)<75 \%$ predicted or $\mathrm{FEV}_{1} /$ forced vital capacity (FVC) $<70 \%$ ) or reversibility of $\mathrm{FEV}_{1} \geqslant 12 \%$ and patients on asthma medication of any type were excluded from the study. Chest and sinus radiographs were performed at the discretion of the physician.

Patients with acute upper respiratory tract infection were asked to return for testing 4 weeks after resolution of symptoms.

Subjects underwent initial measurement of eNO followed by bronchial challenges using $\mathrm{MCH}$, exercise, and AMP. Provocation tests were performed in random order and in a blinded fashion (results of previous challenges and eNO were unknown to the technician performing the study). A minimum of 4 hours washout time was observed between each challenge. This complies with published recommendations. $^{3}$

Local ethics committee approval and informed consent from all participants was obtained for performance of the study.

Abbreviations: AMP, adenosine 5'-monophosphate; eNO, exhaled nitric oxide; $\mathrm{FEV}_{1}$, forced expiratory volume in 1 second; $\mathrm{FVC}$, forced vital capacity; $M C H$, methacholine; $\mathrm{NO}$, nitric oxide 


\section{Follow up}

All patients were assessed by the investigating physicians 24 months after performing provocation studies. A final diagnosis of doctor diagnosed asthma was made by a pulmonary physician (one of the authors) in a blinded fashion-that is, without knowledge of the results of the provocation tests. Patients with documented variability in $\mathrm{FEV}_{1}$ of $\geqslant 12 \%$ at any time over the follow up period, whether in response to bronchodilators given on a single test day ("reversibility") or as determined over time (with or without inhaled corticosteroids or other asthma medication; "variability"), were considered asthmatics. Alternatively, a final diagnosis of asthma was based on patient history only (three or more episodes of doctor recorded wheezing, dyspnoea or cough relieved by bronchodilators) even in the absence of spirometric documentation of reversible airway obstruction. Patients in whom asthma did not manifest within 2 years were considered non-asthmatics. Patients lost to follow up were excluded from further analysis.

\section{Performance of spirometric tests/challenges}

Spirometric tests were performed using a pneumotachograph based system (Vitalograph Compact, Buckingham, UK). Bronchial challenges for $\mathrm{MCH}$ (Spectrum Chemical Corp, Gardena, CA, USA), AMP (Sigma-Aldridge, Rehovot, Israel), and exercise were performed according to recommended guidelines and as previously described. ${ }^{34}$

\section{Measurement of exhaled NO}

Exhaled nitric oxide was measured using a chemiluminescence analyser (LR 2000, Logan Research, Rochester, UK). Patients performed a slow vital capacity exhalation manoeuvre according to recommended guidelines. ${ }^{17}{ }^{27}$ Resistance, mouth pressure $\left(5 \mathrm{~cm} \mathrm{H}_{2} \mathrm{O}\right)$, and flow rate $(250 \mathrm{ml} / \mathrm{s})$ were kept constant for the duration of the manoeuvre using a visual aid for patient guidance. eNO levels were recorded during the plateau phase and coinciding with the plateau phase for exhaled $\mathrm{CO}_{2}$. Three successive recordings were made and the mean value was recorded.

Calibration was performed using 0 and 110 parts per billion (ppb) calibration gas cylinders. Ambient NO levels were measured daily and were always found to be $<3 \mathrm{ppb}$.

Reference values for eNO in known non-atopic nonasthmatics and steroid naive asthmatics measured in our laboratory were as follows (median, 95\% confidence intervals): normal subjects $5.3 \mathrm{ppb}$ (4.90 to 6.97); asthmatics $19.2 \mathrm{ppb}$ (15.15 to 28.82), $(\mathrm{p}<0.0001)$.

\section{Data analysis}

Comparison between tests was performed by constructing receiver operating characteristic (ROC) curves and measurement of area under the curve. ${ }^{28}$ In the ROC plot, the sensitivity (percentage true positive results) is plotted against the percentage false positive results ( $1-$ specificity). The nearer the curve approaches the top left of the ROC plot, the greater the sum of sensitivity and specificity. ROC plots provide a pure index of accuracy of a test by demonstrating the limits of the test's ability to discriminate between health and disease over the complete spectrum of operating conditions. ${ }^{29}$ Quantification of the overall diagnostic accuracy of a test can be expressed by calculating the area under the curve of the ROC plot and provides a value between 0.5 (no separation of test values in healthy and disease groups) and 1.0 (perfect separation). Comparison of AUC is performed according to the method of Hanley and McNeil. ${ }^{28}$

Using clinical follow up to define asthma, the sensitivity and specificity of increasing cut off values of eNO for the diagnosis of asthma were determined. Similar determinations were obtained for exercise, $\mathrm{MCH}$, and AMP challenges.
Optimal cut off values to differentiate asthmatics from nonasthmatics were determined from the highest value obtained by adding sensitivity and specificity. ${ }^{5}$

The diagnostic value of eNO was also determined using positive bronchial provocation tests to define asthma. The optimal cut off value of eNO for the diagnosis of asthma was calculated as above and, using this value, sensitivity, specificity, positive and negative predictive values were determined.

Values for provocation tests and eNO are expressed as medians and interquartile ranges (25-75\%). Correlations between $\mathrm{NO}$ and other provocation tests were determined in the entire cohort and in the asthmatic group of patients using linear regression analysis. In the asthmatic group, subjects with $\mathrm{PC}_{20}$ values higher than the maximal concentration tested were excluded from analysis of correlations only but included for all other analyses.

Comparison between asthmatic and non-asthmatic groups was performed using the Mann-Whitney test. A p value of $<0.05$ was considered significant.

\section{RESULTS}

Symptoms for which patients were referred were as follows: cough $(\mathrm{n}=39)$, dyspnoea $(\mathrm{n}=32)$, cough and dyspnoea $(n=14)$, wheeze $(n=2)$, cough and wheeze $(n=1)$, dyspnoea and wheeze $(n=1)$, and chest tightness $(n=2)$.

Ninety patients completed the initial evaluation including bronchial provocation and eNO determinations. Of these patients, adequate follow up could not be obtained in five. We were left with 85 patients of whom 40 could clearly be classified as asthmatic. The 45 patients in whom a definitive diagnosis of asthma could not be made after 2 years of follow up were considered "non-asthmatic". Because follow up was blinded, final diagnosis in the non-asthma group was determined retrospectively at the end of the 2 year period. Of the non-asthmatics, symptoms resolved over the 2 years in 16 $(35.5 \%)$, were attributed to chronic sinusitis, postnasal drip or allergic rhinitis in $10(22 \%)$, to reflux in four $(9 \%)$, to anxiety attacks in two $(4.5 \%)$, to cardiac failure in two $(4.5 \%)$, and to poor physical conditioning in six (13.4\%). No definitive diagnosis was made in five $(11.1 \%)$ of the remaining cases.

Demographic data and values for lung function, bronchial provocation tests, and eNO levels in asthmatics and nonasthmatics are shown in table 1 and fig 1 . The median (interquartile range) eNO level in asthmatics was $12.7 \mathrm{ppb}$ (8.25-17.1) compared with $3.8 \mathrm{ppb}$ (3.05-5.25) in nonasthmatics $(\mathrm{p}<0.0001)$.

Comparison between tests for the diagnosis of asthma Areas under the curve (AUCs) obtained from ROC curves for eNO, exercise, MCH, and AMP were 0.896, 0.781, 0.924, and

\begin{tabular}{|c|c|c|c|}
\hline & $\begin{array}{l}\text { Asthma } \\
(n=40)\end{array}$ & $\begin{array}{l}\text { Non-asthma } \\
(n=45)\end{array}$ & $p$ value \\
\hline $\begin{array}{l}\text { Age (years)* } \\
\text { Sex }(M: F)\end{array}$ & $\begin{array}{l}21.9(1.6) \\
24: 16\end{array}$ & $\begin{array}{l}29.3(2.4) \\
24: 21\end{array}$ & 0.004 \\
\hline $\mathrm{FEV}_{1}(\% \text { predicted })^{*}$ & $91.9(1.6)$ & $98(1.9)$ & 0.019 \\
\hline $\mathrm{FEV}_{1} / \mathrm{FVC}(\%)^{*}$ & $79(1.1)$ & $82.9(0.8)$ & 0.16 \\
\hline eNO (ppb)† & $12.7(8.25-17.1)$ & $3.8(3.05-5.25)$ & | <0.001 \\
\hline Exercise $\left(\% \Delta \mathrm{FEV}_{1}\right) \dagger$ & $11.5(4-17)$ & $2.0(-1-6)$ & $<0.001$ \\
\hline $\mathrm{MCH}(\mathrm{mg} / \mathrm{ml}) \dagger$ & $0.60(0.25-1.5)$ & $>8$ & $<0.001$ \\
\hline AMP $(\mathrm{mg} / \mathrm{mll} \dagger$ & $23.5(5.25-50)$ & $>400$ & $<0.001$ \\
\hline
\end{tabular}

FEV 1 , forced expiratory volume in 1 second; FVC, forced vital capacity; $M C H$, methacholine; $A M P$, adenosine 5 '-monophosphate. ${ }^{*}$ Mean (SE) values.

†Median (25-75\% percentile range). 

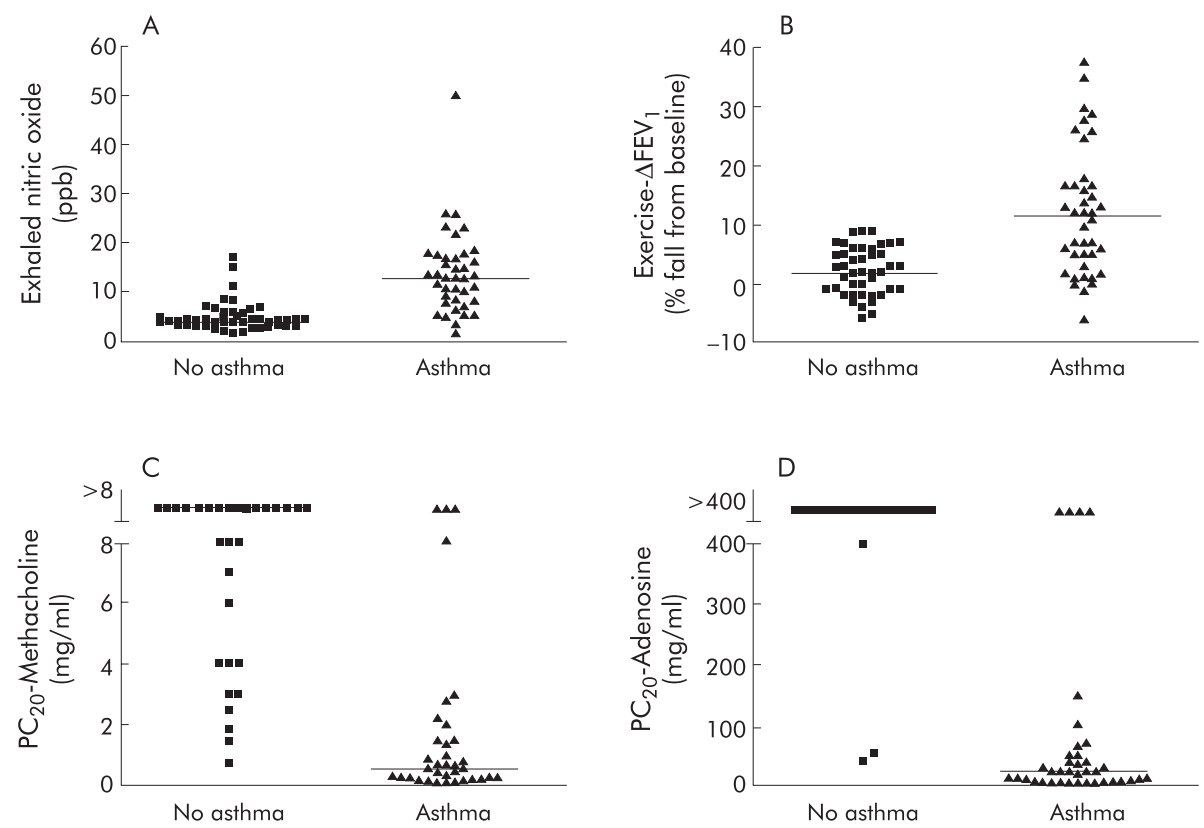

Figure 1 (A) Exhaled nitric oxide levels (ppb), (B) percentage fall in $\mathrm{FEV}$ after exercise, (C) $\mathrm{PC}_{20}$ for methacholine (mg/ml), and (D) $P C_{20}$ for adenosine $5^{\prime}$-monophosphate $(\mathrm{mg} / \mathrm{ml}$ ) in asthmatic and non-asthmatic patients (as defined by clinical follow up). Medians and $95 \%$ confidence intervals for each group are shown in table 2.

0.939, respectively (fig 2). Comparison of AUCs showed that exercise was significantly lower than all other tests but that eNO was similar to MCH and AMP. Comparison of the AUC for eNO with other tests was as follows: exercise, $\mathrm{p}=0.033$; $\mathrm{MCH}, \mathrm{p}=0.57 ; \mathrm{AMP}, \mathrm{p}=0.085$.

\section{Optimal values to define asthma for eNO, MCH, AMP, and exercise}

To define the optimal cut off value for eNO to differentiate asthmatics from non-asthmatics, we constructed curves for sensitivity and specificity of increasing eNO values for the diagnosis of asthma (fig 3) where sensitivity is the number of asthmatics with high eNO/total number of asthmatics and specificity is the number of non-asthmatics with low eNO/ total number of non-asthmatics. The highest sum of these values was considered to be the optimal value to be used as a cut off value for asthma. ${ }^{5}$ A value of eNO $>7 \mathrm{ppb}$ gave a sensitivity of $82.5 \%$ and specificity of $88.9 \%$ for the diagnosis of asthma.

From our data we also determined the optimal cut off values for exercise, $\mathrm{MCH}$, and AMP that differentiate between asthma and non-asthma (table 2).

\section{eNO as a diagnostic test when provocation tests are used to define asthma}

To validate the cut off value we obtained for eNO $(>7 \mathrm{ppb})$ for diagnosing asthma based on clinical follow up, we also calculated the optimal cut off value for eNO when a positive provocation test was used to define asthma $(\mathrm{MCH} \leqslant 3 \mathrm{mg} /$ $\mathrm{ml}$, AMP $\leqslant 150 \mathrm{mg} / \mathrm{ml}$, exercise $\Delta \mathrm{FEV}_{1} \geqslant 10 \%$ ). The sum of the sensitivity and specificity obtained for increasing cut off values of eNO was calculated and the optimal value for eNO was that which gave the highest sum as detailed above. The optimal cut off value for eNO compared with $\mathrm{MCH}, \mathrm{AMP}$, and for exercise was the same for all three tests as that obtained using a clinical definition of asthma ( $>7 \mathrm{ppb})$. Sensitivity, specificity, positive and negative predictive values for eNO $>7 \mathrm{ppb}$ using various gold standards for defining asthma are shown in table 3.

\section{Correlations}

Correlations between eNO and exercise (percentage change in $\left.\mathrm{FEV}_{1}\right), \log \mathrm{PC}_{20}$ for $\mathrm{MCH}$ and AMP were performed in the whole study cohort and repeated in asthmatics only. A significant linear correlation with eNO was found for exercise, MCH, and AMP when all subjects were included, with log-AMP giving the best correlation followed by exercise. Values were $r^{2}=0.41, \mathrm{p}<0.0001$ for $\log$-AMP; $r^{2}=0.31, \mathrm{p}<0.0001$ for exercise; and $r^{2}=0.21, \mathrm{p}<0.0001$ for $\log -\mathrm{MCH}$. When only asthmatics were included and those with assumed values for AMP $(>400 \mathrm{mg} / \mathrm{ml})$ and $\mathrm{MCH}(>8 \mathrm{mg} / \mathrm{ml})$ were excluded, a significant correlation was observed for exercise only but not for log-AMP or for $\log -\mathrm{MCH} \quad\left(r^{2}=0.21, \mathrm{p}=0.003\right.$ for exercise; $r^{2}=0.06$,

Table 2 Optimal cut off values for $\mathrm{eNO}$ and bronchial provocation tests for the diagnosis of asthma

\begin{tabular}{llll}
\hline & Best cut off value & $\begin{array}{l}\text { Sensitivity } \\
\%(95 \% \mathrm{Cl})\end{array}$ & $\begin{array}{l}\text { Specificity } \\
\%(95 \% \mathrm{Cl})\end{array}$ \\
\hline eNO & $>7 \mathrm{ppb}$ & $82.5(67.2$ to 92.7$)$ & $88.9(76.0$ to 96.3$)$ \\
Exercise & $\geqslant 10 \% \mathrm{fall}$ & $57.9(38.5$ to 70.7$)$ & $100(91.8$ to 100$)$ \\
MCH & $\leqslant 3 \mathrm{mg} / \mathrm{ml}$ & $87.5(73.2$ to 95.8$)$ & $86.7(73.2$ to 95.0$)$ \\
AMP & $\leqslant 150 \mathrm{mg} / \mathrm{ml}$ & $89.5(75.2$ to 97.1$)$ & $95.6(84.9$ to 99.5$)$ \\
\hline
\end{tabular}

eNO, exhaled nitric oxide; $M C H$, methacholine; $\mathrm{AMP}$, adenosine $5^{\prime}$-monophosphate. 

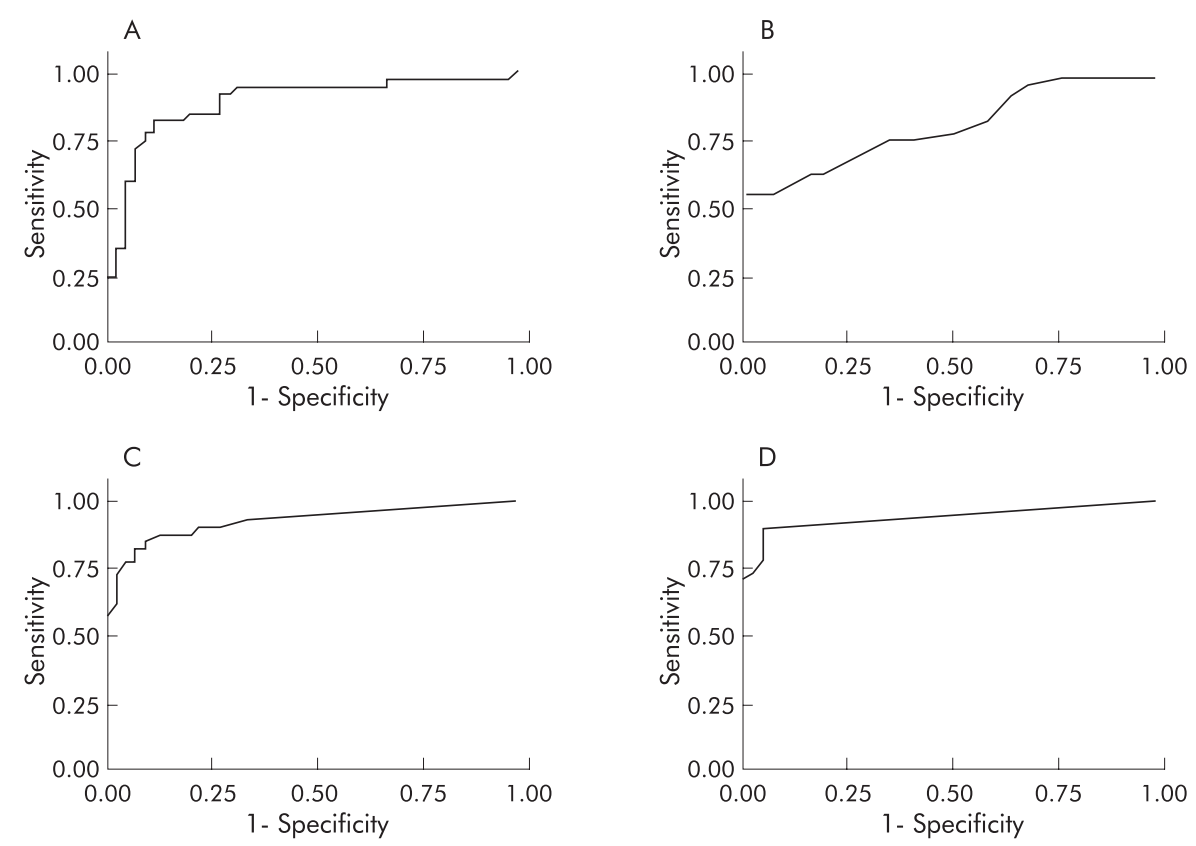

Figure 2 ROC curves obtained for (A) exhaled nitric oxide, (B) percentage fall in $F E V_{1}$ after exercise, (C) $\mathrm{PC}_{20}$ for methacholine, and (D) $P C_{20}$ for $A M P$ in asthmatic and non-asthmatic patients. Area under the curve (AUC) was $0.896,0.781,0.924$, and 0.939 , respectively.

$\mathrm{p}=0.17$ for $\log -\mathrm{AMP}$; and $r^{2}=0.002, \mathrm{p}=0.8$ for $\log -\mathrm{MCH}$; fig 4).

\section{DISCUSSION}

We have performed a prospective study to compare the value of eNO for the diagnosis of asthma with conventional diagnostic tests in patients with non-specific respiratory symptoms. Area under the curve analysis obtained from ROC curves showed that exhaled eNO is a better test than exercise and is as good as MCH and AMP as an aid to the diagnosis of asthma. The optimal value of eNO for the clinical diagnosis of asthma was $>7 \mathrm{ppb}$ at a flow rate of $250 \mathrm{ml} / \mathrm{s}$, with a sensitivity and specificity of $82.5 \%$ and $88.9 \%$, respectively. This sensitivity and specificity was similar to that obtained with $\mathrm{MCH}\left(\mathrm{PC}_{20} \leqslant 3 \mathrm{mg} / \mathrm{ml}\right)$ and superior to exercise $\left(\Delta \mathrm{FEV}_{1}\right.$ $\geqslant 10 \%$ ), although AMP $\left(\mathrm{PC}_{20} \leqslant 150 \mathrm{mg} / \mathrm{ml}\right)$ was superior to other tests including eNO.

For our study we chose to define asthma by clinical follow up. This approach has several advantages. Provocation tests have a significant false positive and negative yield and are therefore in themselves somewhat problematic when used as

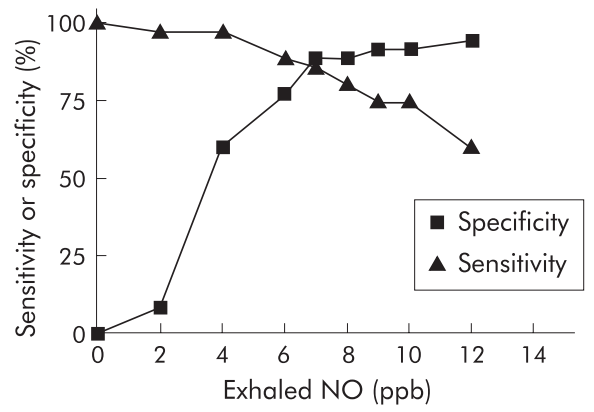

Figure 3 Sensitivity and specificity of increasing cut off values for exhaled nitric oxide in the diagnosis of asthma. An optimal value to differentiate between asthmatics and non-asthmatics was obtained from the highest sum obtained from adding sensitivity and specificity and corresponded to $7 \mathrm{ppb}$. a gold standard for the diagnosis of asthma. Furthermore, the primary aim of our study was to compare the diagnostic value of eNO with these tests. This necessarily excluded them from inclusion in the "gold standard" for the definition of asthma in our study. Rather, we chose a clinical "gold standard" which also included reference to changes in lung function with either bronchodilator or corticosteroids. Irrespective of the "gold standard" chosen, there is always a degree of uncertainty at a single point in time regarding the diagnosis of asthma in some patients. We attempted to overcome this problem by using a prolonged ( 24 month) follow up time, at which point patients were classified as having "doctor diagnosed asthma" or as "non-asthmatic".

Although several studies have shown that eNO is raised in steroid naive asthmatics and that levels correlate with airway inflammation, ${ }^{11-13}$ only a few studies have evaluated this test as a tool for the diagnosis of asthma. Chatkin et $a^{30}$ showed that eNO may be used for diagnosing asthma in patients with chronic cough. Dupont et al ${ }^{24}$ found that measurement of eNO (using a cut off value of $16 \mathrm{ppb}$ ) yielded a specificity of $90 \%$ and a positive predictive value of $>90 \%$ for the diagnosis of asthma. Deykin et $a^{25}$ showed that measurement of eNO allows differentiation between asthmatic patients and healthy subjects, and Smith et al ${ }^{26}$ recently found that eNO is superior to spirometry and peak flow variation and comparable to sputum eosinophilia for the diagnosis of asthma. In contrast to our study, all of these studies used a positive initial response to bronchodilators or a positive challenge test to define the presence of asthma.

Like the studies of Dupont and Smith, ${ }^{24}{ }^{26}$ we felt that performing diagnostic tests including eNO in patients in whom a definitive diagnosis has not yet been establishedrather than testing known asthmatics and non-asthmatic controls-gives more meaningful information because it reflects the real clinical scenario in which we propose that eNO be used.

Physicians may be reluctant to dispense with bronchial provocation tests in favor of eNO for diagnosing asthma. Guidelines define asthma by the presence of reversible 
Table 3 Sensitivity, specificity, positive predictive value (PPV) and negative predictive value (NPV) of eNO $>7 \mathrm{ppb}$ for the diagnosis of asthma using different parameters to define asthma

\begin{tabular}{lllll}
\hline $\begin{array}{l}\text { Parameter defining } \\
\text { asthma }\end{array}$ & Sensitivity (\%) & Specificity (\%) & PPV (\%) & NPV (\%) \\
\hline Clinical & $82.5(33 / 40)$ & $88.9(41 / 45)$ & $89.1(33 / 37)$ & $85.4(41 / 48)$ \\
$M C H \leqslant 3 \mathrm{mg} / \mathrm{ml}$ & $66.7(28 / 42)$ & $72.9(35 / 48)$ & $68.3(28 / 41)$ & $71.4(35 / 49)$ \\
$\mathrm{AMP} \leqslant 150 \mathrm{mg} / \mathrm{ml}$ & $86.5(32 / 37)$ & $81.5(44 / 54)$ & $76.2(32 / 42)$ & $89.8(44 / 49)$ \\
Exercise $\left(\Delta \mathrm{FEV}_{1} \geqslant 10 \%\right)$ & $91.3(21 / 23)$ & $70.1(47 / 67)$ & $51.2(21 / 41)$ & $95.9(47 / 49)$ \\
\hline \multicolumn{2}{l}{ Numbers in brackets are absolute numbers of patients. } \\
\hline
\end{tabular}

airways obstruction which therefore requires performance of spirometric tests and, if normal, bronchial provocation tests. ${ }^{1}$ Nevertheless, airway inflammation is also considered a key element in the diagnosis and pathogenesis of asthma and,
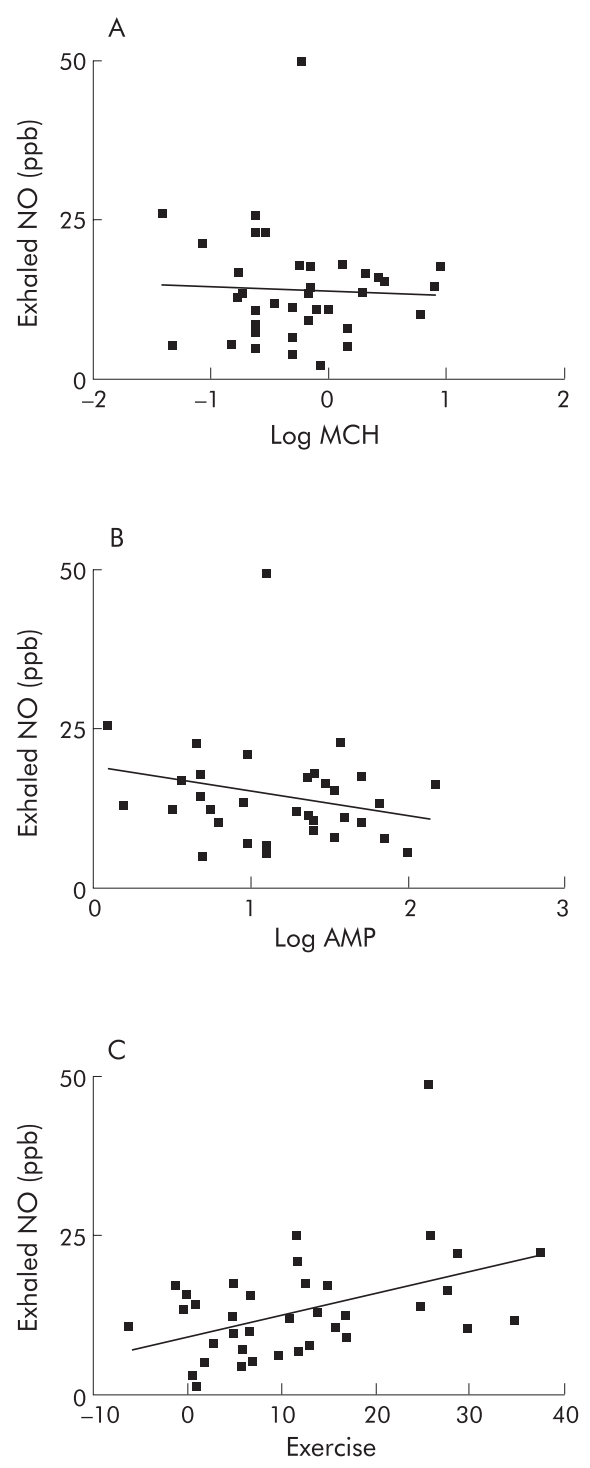

Figure 4 Correlation between eNO and (A) $\log \mathrm{PC}_{20}$ for $\mathrm{MCH}$, (B) log $\mathrm{PC}_{20}$ for $\mathrm{AMP}$, and $(\mathrm{C})$ change in $\mathrm{FEV}$, following exercise in asthmatic subjects. A significant correlation was observed for exercise but not for $\log -\mathrm{MCH}$ or for $\log -\mathrm{AMP}\left(r^{2}=0.21, p=0.003\right.$ for exercise; $r^{2}=0.06$, $p=0.17$ for log-AMP; and $r^{2}=0.002, p=0.8$ for $\left.\log -M C H\right)$. Assumed values $\left(\mathrm{PC}_{20} \geqslant 8 \mathrm{mg} / \mathrm{ml}\right.$ for $\mathrm{MCH}$ and $\geqslant 400 \mathrm{mg} / \mathrm{ml}$ for $\mathrm{AMP}$ ) were excluded from this analysis. while eNO is widely considered to reflect airway inflammation, spirometric testing is at best a poor and inconsistent indicator of inflammation. ${ }^{30}$ There is also controversy as to whether airway hyperresponsiveness as measured by bronchial provocation studies reflects airway inflammation. ${ }^{67}$ Measurement of eNO is extremely easy, quick, and safe to perform, while performance of bronchial provocation tests is time consuming, expensive and associated with some risk, albeit small, of inducing severe bronchospasm. It is therefore not unreasonable to suggest that eNO may be preferable or at least of comparable value to bronchial provocation studies for diagnosing asthma.

We found that an eNO level of $>7 \mathrm{ppb}$ is the optimal single cut off point for differentiating asthmatics from nonasthmatics. We obtained the same optimal cut off value for eNO irrespective of whether asthma was defined by clinical parameters, positive MCH challenge, positive AMP challenge, or by positive exercise test. This consistency adds considerable strength to the validity of the findings in our study. Using a higher or lower cut off value alters the specificity or sensitivity of this test and may be preferable in certain patients depending on pretest probability of asthma. eNO values of $4 \mathrm{ppb}$ yield sensitivity and specificity similar to that of $\mathrm{PC}_{20-} \leqslant 8 \mathrm{mg} / \mathrm{ml}$ for $\mathrm{MCH}$ (sensitivity $95.0 \%$, specificity $57.8 \%$ for eNO, $92.5 \%$ and $66.7 \%$ for $\mathrm{MCH}$ ), while an eNO value of $12 \mathrm{ppb}$ is analogous to a positive exercise test $\left(\Delta \mathrm{FEV}_{1} \geqslant 10 \%\right.$ ) (sensitivity $55 \%$, specificity $95.6 \%$ for $\mathrm{eNO}$, $57.9 \%$ and $100 \%$ for exercise). Clearly, the optimal cut off for eNO for a diagnosis of asthma will depend on the population studied. Our study was performed in a select group with a high prevalence of asthma $(40 / 85,47 \%)$ and different considerations would apply for diagnosing asthma in a less select group of subjects.

Considerable differences in absolute eNO values have been found in different centres. These are related to differences in technique used to measure eNO, the analyser used, and possibly ambient NO levels. ${ }^{17} 2731$ For this study we used an expiratory flow rate of $250 \mathrm{ml} / \mathrm{s}$. ATS guidelines recommend a flow rate of $50 \mathrm{ml} / \mathrm{s}$, although the statement makes it clear that other flow rates can be used. ${ }^{27}$ Our study started before publication of the ATS guidelines and was performed in accordance with ERS guidelines which recommend flow rates of $10-15 \mathrm{l} / \mathrm{min} .{ }^{17}$ eNO has been shown to discriminate between known asthmatics and healthy subjects over a wide range of flow rates (50-250 ml/s for online measurements). ${ }^{25}$ Although attempts have been made to standardise eNO measurements, caution should be used in extrapolating absolute values obtained in one centre to those obtained elsewhere.

In conclusion, we found that eNO can be used as a diagnostic test for asthma in patients presenting with nonspecific respiratory symptoms. This test has high sensitivity and specificity for the diagnosis of asthma, is safe and easy to perform, and has a diagnostic value comparable to that of conventional bronchial provocation tests. 


\section{Authors' affiliations}

N Berkman, A Avital, R Brever, E Bardach, C Springer, S Godfrey, Institute of Pulmonology, Hadassah-Hebrew University Medical Center, Jerusalem, Israel

\section{Sponsors: none}

The contributing authors have no competing interests related to this publication.

\section{REFERENCES}

1 National Institutes of Health. Guidelines for the diagnosis and management of asthma. Bethesda, MD: NIH, National Heart, Lung, and Blood Institute, 1997.

2 American Thoracic Society. Standards for the diagnosis and care of patients with chronic obstructive pulmonary disease (COPD) and asthma. Official statement of the American Thoracic Society. Am Rev Respir Dis 1987; 136:225-44.

3 Crapo RO, Casaburi R, Coates AL, et al. Guidelines for methacholine and exercise challenge testing - 1999. Am J Respir Crit Care Med 2000; 161:309-29.

4 Avital A, Springer C, Bar-Yishay E, et al. Adenosine, methacholine and exercise challenges in children with asthma or paediatric chronic obstructive pulmonary disease. Thorax 1995:50:511-6.

5 Godfrey S, Springer C, Bar-Yishay E, et al. Cut-off points defining normal and asthmatic bronchial reactivity to exercise and inhalation challenges in children and young adults. Eur Respir J 1999;14:659-68.

6 Avital A, Godfrey S, Springer C. Exercise, methacholine and adenosine 5' monophosphate challenges in children with asthma: relation to severity of disease. Pediatr Pulmonol 2000;30:207-14.

7 Bentley AM, Menz G, Storz C, et al. Identification of T-lymphocytes, macrophages and activated eosinophils in the bronchial mucosa of intrinsic asthma: relationship to symptoms and bronchial hyperresponsiveness. Am Rev Respir Dis 1992; 146:500-6.

8 Gustafsson LE, Leone AM, Persson MG, et al. Endogenous nitric oxide is present in the exhaled air of rabbits, guinea-pigs and humans. Biochem Biophys Res Commun 1991:181:852-7.

9 Kharitonov SA, Yates D, Robbins RA, et al. Increased nitric oxide in exhaled air of asthmatic patients. Lancet 1994;343:133-5.

10 Alving K, Weitzberg E, Lundberg JM. Increased amount of nitric oxide in exhaled air of asthmatics. Eur Respir J 1993:6:1368-70.

11 Al-Ali MK, Eames C, Howarth PH. Exhaled nitric oxide: relationship to clinicophysiological markers of asthma severity. Respir Med 1998;92:908-13.

12 Jatakanon A, Lim S, Kharitonov SA, et al. Correlation between exhaled nitric oxide, sputim eosinophils, and methacholine responsiveness in patients with mild asthma. Thorax 1998;53:91-5.

13 Lim S, Jatakanon A, Meah S, et al. Relationship between exhaled nitric oxide and mucosal eosinophilc inflammation in mild to moderately severe asthma. Thorax 2000;55:184-8.
14 Van Rensen EU, Straathof KCM, Veselic-Charvat MA, et al. Effect of inhaled steroids on airway hyperresponsiveness, sputum eosinophils, and exhaled nitric oxide levels in patients with asthma. Thorax 1999;54:403-8.

15 Al-Ali MK, Howarth PH. Nitric oxide and the respiratory system in health and disease. Respir Med 1998;92:701-15.

16 Silkoff PE, Caramori M, Tremblay L, et al. Exhaled nitric oxide in human lung transplantation. A noninvasive marker of acute rejection. Am J Respir Crit Care Med 1998;157:1822-8.

17 Kharitonov S, Alving K, Barnes PJ. Exhaled and nasal nitric oxide measurements: recommendations. ERS Task Force Report. Eur Respir J 1997; 10:1683-93.

18 Kharitonov SA Yates D, Barnes PJ Increased nitric oxide in exhaled air of normal human subjects with upper respiratory tract infections. Eur Respir J 1995;8:295-7.

19 Maziak W, Loukides S, Culpitt S, et al. Exhaled nitric oxide in chronic obstructive pulmonary disease. Am J Respir Crit Care Med 1998;157:998-1002

20 Dotsch J, Demirakca S, Terbrack HG, et al. Airway nitric oxide in asthmatic children and patients with cystic fibrosis. Eur Respir J 1996;9:2537-40.

21 Kharitonov SA, Robbins RA, Yates D, et al. Acute and chronic effects of cigarette smoking on exhaled nitric oxide. Am J Respir Crit Care Med 1995; 152:609-12.

22 Deykin A, Halpern O, Massaro AF, et al. Expired nitric oxide after bronchoprovocation and repeated spirometry in patients with asthma. Am J Respir Crit Care Med 1998;157:769-75.

23 Persson MG, Wiklund NP, Gustafsson LE. Endogenous nitric oxide in single exhalations and the change during exercise. Am Rev Respir Dis 1993; 148:1210-4.

24 Dupont L, Demedts MG, Verleden GM. Prospective evaluation of the validity of exhaled nitric oxide for the diagnosis of asthma. Chest 2003; 123:751-6.

25 Deykin A, Massaro AF, Drazen JM, et al. Exhaled nitric oxide as a diagnostic test for asthma. Am J Respir Crit Care Med 2003;165:1597-601.

26 Smith AD, Cowan JO, Filsell S, et al. Diagnosing asthma. Comparisons between exhaled nitric oxide measurements and conventional tests. Am J Respir Crit Care Med 2004; 169:473-8.

27 American Thoracic Society. Recommendations for standardized procedures for the online and offline measurement of exhaled lower respiratory nitric oxide and nasal nitric oxide in adults and children - 1999. Official statement of the American Thoracic Society. Am J Respir Crit Care Med 1999; 160:2104-17.

28 Hanley JA, McNeil BJ. A method of comparing the areas under receiver operating characteristic curves derived from the same cases. Radiology 1983;148:839-43.

29 Zweig MH, Campbell G. Receiver-Operating Characteristic (ROC) plots: a fundamental tool in clinical evaluation. Clin Chem 1993;39:561-77.

30 Chatkin JM, Ansarin K, Silkoff PE, et al. Exhaled nitric oxide as a noninvasive assessment of chronic cough. Am J Respir Crit Care Med 1999;159:1810-3.

31 Byrnes CA, Dinarevic S, Busst CA, et al. Effect of measurement conditions on measured levels of peak exhaled nitric oxide. Thorax 1997;52:697-701. 